\title{
Instituto Brasileiro de Direito Comercial Comparado e Biblioteca Tullio Ascarelli.
}

Tendo sido doado a esta Faculdade valiosíssimo acêrvo bibliográfico, parte da biblioteca do saudoso professor Tullio Ascarelli, tiveram os professôres de Direito Comercial desta Faculdade a possibilidade de concretizar antigo ideal, com a fundação a 11 de agôsto do corrente ano, do Instituto Brasileiro de Direito Comercial Comparado.

Publica-se a seguir a escritura pública de constituição do Instituto, que diz muito bem dos objetivos e do alto significado da criação para desenvolvimento do estudo do Direito Comercial Comparado.

\section{Escritura pública da fundação.}

Saibam quantos a presente escritura pública de Fundação virem, que, no ano de mil novecentos e sessenta e dois, aos onze dias do mês de agôsto, nesta cidade de São Paulo, no escritório do Professor Doutor Waldemar Martins Ferreira, à Rua da Quitanda n. 139, e acompanhados do Exmo. Sr. Diretor da Faculdade de Direito da Universidade de São Paulo, Professor Doutor Luís Antônio da Gama e Silva, e do Exmo. Sr. Curador de Resíduos desta Comarca, Doutor Mário de Salles Penteado, compareceram, perante mim Tabelião, como instituidoras, as seguintes 61 (sessenta e uma) entidades :

Associação Comercial de São Paulo Bôlsa Oficial de Valores de São Paulo Centro das Indústrias do Estado de São Paulo 
Departamento Regional do Serviço Social da Indústria - São Paulo

Federação do Comércio do Estado de São Paulo Sociedade Rural Brasileira

Banco do Estado de São Paulo S.A.

Banco Brasileiro de Descontos S.A.

Banco Comercial do Estado de São Paulo S.A.

Banco do Comércio e Indústria de São Paulo S.A.

Banco Federal de Crédito S.A.

Banco Francês e Brasileiro S.A.

Banco Itaú S.A.

Banco Mercantil de São Paulo S.A.

Banco Moreira Salles S.A.

Banco Nacional do Comércio de São Paulo S.A.

Banco Noroeste do Estado de São Paulo S.A.

Banco de São Paulo S.A.

Banco Sul Americano do Brasil S.A.

Caixa Econômica Federal de São Paulo

Cia. Brasileira de Investimentos - C.B.I

Cia. Sul Americana de Investimentos, Crédito e Financiamento

Deltec S.A. - Financiamento, Crédito e Investimentos

S.A. Financiadora Industrial e Comercial "SAFIC" Sociedade Campos Fraga de Valores Ltda.

Aços Villares S.A.

Artefatos de Alumínio e Embalagens "Ardea" S.A.

Brasmotor S.A. Empreendimentos e Participações

Caterpillar do Brasil S.A. - Máquinas e Peças

Cia. Comercial de Vidros do Brasil - C.V.B.

Cia. Fiat Lux de Fósforos de Segurança

Cia. Incentivadora de Atividades Agricolas e Industriais

Cia. Melhoramentos de São Paulo - Indústrias de Papel

Cia. Química Rhodia Brasileira 
Cia. Ultragaz S.A.

Cia. União dos Refinadores - Açúcar e Café

Conexões de Ferro Foz S.A.

Duratex S.A. - Indústria e Comércio

Fábrica Nacional de Vagões S.A.

Fundação São Domingos

Grupo Atlântica de Seguros, constituído por Atlântica - Cia. Nacional de Seguros, Transatlântica - Cia. Nacional de Seguros, Oceânica - Cia. Brasileira de Seguros e Ultramar - Cia. Brasileira de Seguros

Indústria e Comércio de Minérios S.A. - ICoMI Indústrias Químicas Eletro Cloro S.A.

Indústrias Villares S.A.

Liquigás do Brasil S.A.

Manufatura de Brinquedos Estrela S.A.

Mercedez-Benz do Brasil S.A.

Metalúrgica Matarazzo S.A.

Modas A Exposição Clipper S.A.

Pancostura S.A. - Indústria e Comércio

Plásticos Plavinil S.A.

Química Industrial Medicinalis S.A.

Real S.A. - Transportes Aéreos

Revisora Nacional Ltda. S/C - Peritos em Contabilidade

S.A. Moinho Santista - Indústrias Gerais

Singer Sewing Machine Co.

Sociedade Técnica de Fundições Gerais S.A. SOFUNGE

Tecelagem Paraíba S.A.

Ultralar-Aparelhos e Serviços Ltda.

Willys Overland do Brasil S.A. - Indústria e Comércio

- pessoas jurídicas assim sediadas: Banco Moreira Salles S.A., na cidade de Poços de Caldas, Estado de Minas Gerais; Cia. Fiat Lux de Fósforos de Segurança, Cia. Incentivadora 
de Atividades Agrícolas e Industriais, Grupo Atlântica de Seguros e Willys Overland do Brasil S.A. - Indústria e Comércio, na cida" de do Rio de Janeiro, Estado da Guanabara; Cia. Química Rhodia Brasileira, na cidade de Santo André, Estado de São Paulo; Indústria e Comércio de Minérios S.A. - ICOMI, na cidade de Belo Horizonte, Estado de Minas Gerais; Mercedes-Benz do Brasil S.A., na cidade de São Bernardo do Campo, Estado de São Paulo; e as restantes nesta cidade de São Paulo — tôdas neste ato representadas, a Caixa Econômica Federal de São Paulo, por seu Sub-Procurador Geral, Doutor Luiz de Oliveira Coutinho, brasileiro, casado, advogado, domiciliado e residente na capital de São Paulo, e as demais, por seus bastantes procuradores Doutores Waldemar Martins Ferreira, Ernesto de Moraes Leme, Honório Fernandes Monteiro, Sylvio Marcondes, Oscar Barreto Filho e Philomeno Joaquim da Costa, brasileiros, casados, professôres, domiciliados e residentes na Capital de São Paulo, conforme instrumentos de mandato com poderes especiais, que me foram apresentados, para fazerem parte integrante desta escritura, e ficam arquivados e registrados em meu cartório; os presentes meus conhecidos, bem como das duas testemunhas adiante nomeadas e assinadas, do que dou fé.

$\mathrm{E}$, perante elas, pelas instituidoras, por seus mencionados procuradores, me foi dito que:

1. considerando que o Direito Comparado, como método de trabalho científico - consistente no estudo comparativo dos diversos sistemas nacionais, pelo confronto da legislação, jurisprudência e doutrina respectivas, equiparan- 
do ou diferenciando os diversos institutos jurídicos, não só no espaço, como no tempo, através de sua evolução permite verificar as afinidades das instituições jurídicas dos diversos países, considerados individuadamente ou em grupos, fornecendo dados para eventual unificação do direito, nos ramos em que ela seja desejável;

2. considerando que, afóra êsse efeito, de realização mais remota, o método comparativo pode produzir, entre outros e desde logo, no campo do direito nacional, proveitosos resultados, de três ordens: a) interpretação mais segura e extensiva das normas de direito positivo, em virtude do conhecimento do modo pelo qual as instituições corres pondentes funcionam nos demais sistemas legislativos, extraindo-se de cada instituto o máximo de possibilidades de aplicação, sem modificar-se o direito interno; b) aproveitamento de teorias e práticas adotadas em outros países, que possam, sem ofensas aos princípios que informam o nosso sistema legal, favorecer seu aperfeicoamento, sugerindo reformas ou emendas legislativas; c) consolidação da doutrina nacional, pela reafirmação, após o estudo comparativo, da excelência de certos institutos, tal como estão jả regulados;

3. considerando que êsses benefícios mais se acentuam, quando se trata de estudo comparativo do Direito Comercial, pois sua universalidade, decorrente do tráfico mercantil internacional, constitui solicitação constante de aproximação dos direitos nacionais;

4. considerando que a contínua evolução dos negócios, cujas técnicas se difundem ràpidamente por todos os paises, exige um permanente esfôrço de adaptação, no aplicarem-se os preceitos legais que os regulam, a bem do qual nitidamente se refletem os mencionados proveitos do método comparativo, acrescidos, na prática comercial, da vantagem de permitir melhor contribuição dos juristas do país, no 
esclarecimento dos empresários estrangeiros que nêle desejam estabelecer-se;

5. considerando que o Direito Comparado constitui no Brasil objeto de disciplina incluída no currículo de algumas Faculdades, mas a aplicação do método comparativo não tem avançado além do trabalho individual de escritores, isolados em seu esfôrço, sem a cooperação de um trabalho de equipe, principalmente porque, no ramo específico da matéria mercantil, o comércio nacional oferece pouco estímulo a êsses estudos, que, por suas finalidades, se realizam acentuadamente nas nações de economia plenamente desenvolvida;

6. considerando, porém, que o surto industrial ora verificado em nosso país, com tôdas as suas influências de ordem econômica, jurídica e social, vem demonstrando a necessidade de instituir-se entidade que congregue todos os que se dediquem, ou queiram dedicar-se, aos estudos de Direito Comercial Comparado, indispensáveis para que o progresso da ciência jurídica possa acompanhar e auxiliar eficazmente o desenvolvimento econômico nacional;

7. considerando, ademais, que o engrandecimento do Direito, no campo internacional, e o aprimoramento da leis nacionais, que com o mesmo se relacionam, constituem inestimável instrumento para a melhoria do entendimento entre as nações, a benefício da paz e do progresso dos povos;

8. considerando que a conjugação dêsses fatôres amadureceu, no espírito dos professôres de Direito Comercial da Faculdade de Direito da Universidade de São Paulo, o intento da criação de um Instituto de Direito Comercial Comparado, com o objetivo de reunir esforços dispersos por todo o país, criando condições que permitam colher, para êste, os proveitos já indicados, em favor, especialmente, da revisão do nosso quadro legislativo que, em matéria mercantil, se vai tornando incompleto e obsoleto; 
9. considerando que, dada a natureza do trabalho programado, a iniciativa exigia, desde logo, a instalação de biblioteca especializada, suficientemente rica para permitir resultados de valor, na complexidade e variedade das legislações e doutrinas estrangeiras;

10. considerando que tal condição veio a ser satisfeita, graças à realização póstuma do desejo manifestado pelo eminente e saudoso professor Tullio Ascarelli, e ao qual deu cumprimento sua família, fazendo doação à Faculdade de Direito, de parte valiosa da biblioteca daquele grande mestre de Roma, que, emérito comercialista, se dedicou profìcuamente aos estudos do Direito Comercial Comparado;

11 considerando que, por deliberação da Congregação da Faculdade, a biblioteca deverá ser conservada, como acêrvo bibliográfico autônomo, separada da Biblioteca Geral, e mantida em instalações próprias, na sede da Faculdade, sob a administração e cuidados do Instituto que vem sendo organizado com êsse fim, por seus professôres de Direito Comercial, para isso constituídos em comissão;

12. considerando que o Instituto terá por objetivo: a) reunir e coordenar a colaboração de todos os juristas professôres, advogados, magistrados - que, dedicados à ciência jurídica mercantil, queiram empenhar-se em estudos e pesquisas de Direito Comercial Comparado; b) promover cursos, seminários, conferências e outras formas de atividade, inclusive intercâmbio com juristas estrangeiros e entidades congêneres; c) cooperar com os poderes públicos, ministrando-lhes trabalhos e projetos de sua especialidade; d) constituir biblioteca, composta dos livros e revistas que venha a adquirir e das referidas obras doadas à Faculdade de Direito, imprimindo-lhe estrutura técnica, mediante organização de fichários completos da matéria nela contida; e) mantê-la em estado dinâmico, por meio de serviços de pesquisa, tendentes à realização das precípuas finalidades do método comparativo; f) editar revistas, boletins e pu- 
blicações avulsas, compendiando os trabalhos realizados, para dar-lhes, nos meios interessados, ampla divulgação; g) outras atividades, que, concernentes aos mesmos fins, a experiência e o próprio funcionamento do Instituto venham a indicar como aconselháveis;

13. considerando que a realização de tão altas finalidades exigirá, além de indispensáveis gastos de instalação, o dispêndio permanente de recursos de manutenção, cujo montante, maior ou menor, influirá na produtividade da instituição, e que o Instituto, não obstante poder contar com o apoio da Faculdade de Direito e da Universidade de São Paulo - mediante auxílios de pessoal, local e material - a limitação dos seus respectivos orçamentos difìcilmente proporcionará expansão capaz de assegurar-lhe plena eficiência, circunstâncias que tornam acertado e aconselhável constituir-se uma Fundação, dotada de patrimônio próprio e adequado, apto a proporcionar, por sua renda, auxílio apreciável e constante, em refôrço de outros recursos, oficiais ou particulares, que lhe sejam destinados;

14. considerando que a atividade do Instituto, embora acentuadamente cultural, produzirá resultados práticos da mais alta importância, na solução de problemas jurídicos intimamente relacionados com o progresso da economia nacional, o que justifica o interêsse das entidades mais diretamente responsáveis pelo desenvolvimento da mesma economia, na concretização daquele programa;

15. considerando que a sua Comissão Organizadora, confiante na elevada compreensão do interêsse público, que inspira e anima essas entidades, se propôs coordenar aquêle interêsse, dirigindo-lhes convite, prontamente aceito, para formarem, mediante a contribuição de cada uma, o patrimônio inicial da Fundação -

Resolvem, por fôrça da presente escritura e da coexistência dos elementos necessários à constituição de uma Fundação: 
1. $)$ instituir uma Fundação, denominada "Instituto Brasileiro de Direito Comercial Comparado e Biblioteca Tullio Ascarelli", destinada à realização dos fins acima especificadamente relacionados;

$2^{\circ}$ ) formar o seu patrimônio inicial, no montante de $\mathrm{Cr} \$ 12.200 .000,00$ (doze milhões e duzentos mil cruzeiros), mediante a dotação especial que lhe faz cada uma das 61 (sessenta e uma) pessoas jurídicas instituidoras, da quantia de $\operatorname{Cr} \$ 200.000,00$ (duzentos mil cruzeiros) em dinheiro, que se obrigam a realizar em 10 (dez) prestações de Cr $\$$ $20.000,00$ (vinte mil cruzeiros), vencíveis mensalmente, a partir da data desta escritura;

3. ) dar corpo jurídico à Fundação, estabelecendo-lhe os seguintes estatutos:

\section{Instituto Brasileiro de Direito Comercial Comparado e Biblioteca Tullio Ascarelli.}

\section{Estatutos}

Da denominação, sede, objeto e duração.

Art. 1.․ O "Instituto Brasileiro de Direito Comercial Comparado e Biblioteca Tullio Ascarelli" é uma fundação, instituída por escritura pública de 11 de agôsto de 1962 (notas do Tabelião Veiga, $11 .^{\circ}$ Ofício de Notas da Capital de São Paulo, livro 1.984, fls. 42), com-sede e fôro na cidade de São Paulo, e funcionará, enquanto possível, em dependências cedidas pela Faculdade de Direito da Universidade de São Paulo.

Art. 2. ${ }^{\circ}$ A Fundação tomará a seu cargo a guarda e conservação das obras doadas pelos sucessores do Professor Tullio Ascarelli à Faculdade de Direito, da qual receberá auxílios de pessoal, local e material, nas condições que forem aprovadas por sua Congregação. 
Art. 3. . A Fundação terá por objeto:

a) reunir e coordenar a colaboração de todos os juristas - professôres, advogados, magistrados - que, dedicados à ciência jurídica mercantil, queiram empenhar-se em estudos e pesquisas de Direito Comercial Comparado;

b) promover cursos, seminários, conferências e outras formas de atividade, inclusive intercâmbio com juristas estrangeiros e entidades congêneres;

c) cooperar com os poderes públicos, ministrando-lhes trabalhos e projetos de sua especialidade;

d) constituir biblioteca, composta dos livros e revistas que venha a adquirir e das referidas obras doadas à Faculdade de Direito, imprimindo-lhe estrutura técnica, mediante, organização de fichários completos da matéria nela contida;

e) mantê-la em estado dinâmico, por meio de serviços de pesquisa, tendentes à realização das precípuas finalidades do método comparativo;

f) editar revistas, boletins e publicações avulsas, compendiando os trabalhos realizados, para dar-lhes, nos meios interessados, ampla divulgação;

g) conferir, periódica e regularmente, o "Prêmio Tullio Ascarelli", de conformidade com o regimento de concurso, que especialmente se aprovar, a autor de monografia de Direito Comercial Comparado, e instituir outros prêmios, que despertem maior interêsse pela especialidade, estimulando seu estudo;

h) outras atividades, que, concernentes aos mesmos fins, a experiência e o próprio funcionamento da Fundação venham a indicar como aconselháveis.

Art. 4. ${ }^{\circ}$ A Fundação, como pessoa jurídica de caráter perpétuo, não tem prazo nem condições de extinção; mas se vier a perecer por qualquer circunstância inesperada, que a impossibilite de realizar, com os próprios recursos, seus objetivos, o seu patrimônio se incorporará no da Faculdade de Direito da Universidade de São Paulo, para que ela os realize. 
Dos membros da fundação.

Art. 5.․ A Fundação terá membros, que contribuam para a sua finalidade, das seguintes categorias: I, os efetivos; II, os titulares; III, os patrocinadores; IV, os correspondentes; $\mathrm{V}$, os honorários.

$\S 1^{\circ}$ ) Serão membros efetivos os doutores ou bacharéis em direito, que solicitarem sua admissão, mediante proposta do interessado e parecer favorável de comissão de admissão, homologado pela Junta Administrativa.

$\left.\S 2^{\circ}{ }^{\circ}\right)$ Serão membros titulares os catedráticos e livres docentes da Faculdade de Direito da Universidade de São Paulo, por sua investidura; e, mediante requerimento, os catedráticos ou livres docentes de Direito Comercial, das Faculdades de Direito nacionais, oficiais ou reconhecidas, nomeados por concurso, na forma da lei.

$\S 3 .^{\circ}$ ) Serão membros patrocinadores os instituidores da Fundação e as pessoas naturais ou jurídicas que, em razão de seu reconhecido merecimento, sejam convidadas pela Junta Administrativa.

$\S 4^{\circ}$ ) Serão membros correspondentes os professôres universitários, nacionais ou estrangeiros, nomeados para representar, permanente ou temporàriamente, a Fundação, fora de sua sede.

$\S 5^{\circ}$ ) Serão membros honorários os juristas que, por suas obras ou títulos, mereçam, a critério do Conselho Diretor, a homenagem da Fundação.

Art. $6{ }^{\circ}$. Os membros da Fundação terão livre ingresso nos seus departamentos e serviços e poderão realizar em sua sede, com a anuência do Conselho Diretor, conferências, seminários ou cursos.

Art. 7. Os membros ef etivos - bem como, facultativamente, os das demais categorias - contribuirão, semestralmente, com o subsidio que o regimento interno determinar. 
Art. 8. . A Fundação expedirá a seus membros, de tôdas as categorias, diploma condigno, entregue na forma a ser estabelecida pelo regimento interno, constituindo título que seu portador poderá usar pùblicamente.

\section{Do patrimônio.}

Art. 9. ${ }^{\circ}$ Constituem o patrimônio inicial da Fundação as contribuições prestadas por seus instituidores, na conformidade da escritura de constituição, cujo montante será integral e permanentemente aplicado numa carteira de valores mobiliários, formada com títulos públicos ou particulares, cotados em Bolsa, de notória segurança e bôa rentabilidade.

Parágrafo único - Dos lucros e rendimentos líquidos, auferidos dêsses títulos:

a) serão incorporados à carteira os títulos recebidos como bonificação, bem como metade dos lucros recebidos em dinheiro, por ágios ou deságios na alienação ou aquisição de quaisquer títulos;

b) a outra metade dos ditos lucros e, ainda, os dividendos e juros percebidos pela carteira, serão destinados à realização dos serviços da Fundação, com o emprêgo de $50 \%$ do total, pelo menos, na aquisição de livros e revistas que interessem aos seus objetivos.

Art. 10. A Fundação poderá receber, para acréscimo e melhoramento de seu patrimônio ou execução de seu pro. grama, subsidios, subvenções, doações ou legados.

\section{Da administração.}

Art. 11. A administração da Fundação caberá, nos têrmos dêstes estatutos, a três órgãos colegiados:

a) a Junta Administrativa;

b) o Conselho Diretor; 
c) o Conselho de Patrocinadores.

Art. 12. A Fuṇdação será gerida pela Junta Admịniștrativa, constituída cada dois anos e composta dos catedráticos de Direito Comercial da Faculdade de Direito da Universidade de São Paulo, efetivos ou aposentados, que aceitem o encargo; de dois livres docentes da mesma disciplina; de dois membros patrocinadores, ou seus delegados, se forem pessoas jurídicas; êstes quatro últimos, eleitos por aquêles primeiros.

Parágrafo ưnico - Se na sua organização bienal, ou no curso do mandato, a Junta ficar constituída com menos de quatro daqueles catedráticos, caberá à Congregacãa dạ Faculdade eleger outros, para preenchimento dệsse número.

Art. 13. A Junta Administrativa, dentre seus membros, escolherá o Presidente, o Tesoureiro e o Secretário da Fundação, podendo ainda atribuịr, a qualquer outro, o exercício de determinadas funções específicas, e providenciará, observando o disposto no artigo anterior e seu parágrafo, as substituições necessárias, nos cạsos de vaga, licença, ausência ou impedimento.

Parágrafo único - A Junta Administrativa reunịr-se-á por convocação do Presidente, de iniciativa própria ou a pedido de qualquer de seụs membros, e deliberará, vàlidamente, com a presença da maioria dêleș.

Art. 14. Além de outras atribuições, próprias da gestão de bens, ou previstas nestes estatutos, compete à Junta Administrativa :

a) estabelecer o plano de administração dos bens da Fundação, os quais não poderão ser objeto de ônus reais;

b) decidir sôbre a aquisição ou alienação de quaisquer bens, inclusive os títulos componentes da carteira de valores mobiliários, dependendo, entretanto, de autorização judicial, a alienação de bens imóveis;

c) elaborar o regimento interno da Fundação, organizar os seus serviços e aprovar a nomeação e demissão dos seus funcionários; 
d) autorizar o contrato com emprêsa especializada, de notória idoneidade, que organize e mantenha a contabilidade;

e) fazer, até o fim de cada ano, a previsão orçamentária do exercício seguinte, fixando, para a despesa, verba não excedente de receita assegurada, ou já percebida, mesmo em exercícios anteriores, conforme o disposto no art. 9. , parágrafo único, alínea " $b$ ";

f) tomar conhecimento dos balancetes mensais e fazer publicar, semestralmente, a demonstração da receita obtiđa e da despesa realizada no período anterior;

g) fazer levantar o balanço anual, elaborando o relatório correspondente.

Art. 15. Compete ao Presidente:

a) convocar e presidir, acumulando voto de qualidade, as reuniões dos órgãos de administração;

b) representar a Fundação nas suas relações com terceiros, em juízo ou fora dêle;

c) assinar, em conjunto com o Tesoureiro, os atos e documentos, de natureza obrigacional, da Fundação.

Art. 16. Compete ao Tesoureiro:

a) promover a execução das deliberações da Junta Administrativa, referentes a bens da Fundação;

b) manter os seus valores em custódia, ou depósito, em Bancos designados pela Junta Administrativa;

c) assinar, com o Presidente, os atos e documentos referidos na alínea " $\mathrm{c}$ " do artigo anterior.

Art. 17. Compete ao Secretário:

a) colaborar com o Presidente e o Tesoureiro no desempenho dos encargos que lhes incumbem;

b) superintender os serviços de secretaria da Fundação, assinando a respectiva correspondência;

c) dirigir a redação de atas das reuniões dos órgãos da administração.

Art. 18. As atividades culturais, científicas e técnicas, da Fundação, adequadas à realização de seus fins, serão 
organizadas e dirigidas pelo Conselho Diretor, cujo mandata coincidirá com o da Junta Administrativa, composto dos membros desta e de um representante designado, respectivamente, pelo Tribunal de Justiça de São Paulo, pelo Conselho Superior do Ministério Público de São Paulo, pela Ordem dos Advogados do Brasil - Secção de São Paulo e por Faculdades de Direito que, pertencentes a Universidades, tenham sede na cidade de São Paulo.

Parágrafo único. O Conselho Diretor reunir-se-á, ordinàriamente, cada trimestre, convocado pelo Presidente e, extraordinàriamente, quando êste julgar necessário, deliberando, vàlidamente, com a presença da maioria de seus membros.

Art. 19. A gestão administrativa e a atividade cultural da Fundação - mediante relatórios da Junta Administrativa e do Conselho Diretor, aquêle acompanhado de parecer de emprêsa auditora de contabilidade, de notória idoneidade - serão submetidas anualmente à aprovação do Conselho de Patrocinadores, formado, em caráter vitalício, pelos membros patrocinadores.

Parágrafo único. O Conselho de Patrocinadores reunir-se-á, ordinàriamente, no primeiro trimestre de cada ano, convocado pelo Presidente e, extraordinàriamente, quando êste julgar necessário, deliberando, vàlidamente, em primeira convocação, com a presença da maioria de seus membros, e, em segunda, com a de qualquer número.

\section{Disposições gerais.}

Art. 20. Os cargos dos órgãos da administração não serão remunerados, bem como não serão atribuidos lucros, bonificações ou vantagens, sob nenhuma forma ou pretexto, aos dirigentes, mantenedores ou membros da Fundação.

Art. 21. Os membros da Fundação ou dos seus órgãos de administração não responderão, nem solidária, nem sub- 
sidiàriamente, pelas obrigações por ela ou em nome dela contraídas.

Art. 22. Os presentes estatutos, com resguardo dos fins da Fundação e por proposta fundamentada da maioria dos membros componentes da Junta Administrativa, poderão ser alterados, mediante deliberação, por maioria absoluta, do Conselho Diretor, aprovada pelo Conselho de Patrocinadores e pela Congregação da Faculdade de Direito da Universidade de São Paulo.

$\mathrm{E}$ assim, têm por constituída a Fundação "Instituto Brasileiro de Direito Comercial Comparado e Biblioteca Tullio Ascarelli", dependente da aprovação do Ministério Público.

Neste ato, pelo Exmo. Sr. Diretor da Faculdade de Direito da Universidade de São Paulo, Professor Doutor Luiz Antonio da Gama e Silva, me foi dito, na presença das duas aludidas testemunhas: $1^{\circ}$ ) que, diante da deliberação tomada pela Egrégia Congregação de seus Professôres, aprovando a proposta de criação da Fundação, ora instituída, na conformidade dos estatutos acima transcritos, se declarava de acôrdo com a presente escritura; $2 .^{\circ}$ ) que, tendo o Banco do Brasil S.A., em atenção a convite da Comissão Organizadora da Fundação, feito a doação de $\operatorname{Cr} \$ 200.000,00$ (duzentos mil cruzeiros) à Faculdade de Direito, como auxílio para criação do Instituto, tal quantia fica desde agora à disposição da Fundação, para atender às despesas de sua constituição, inclusive as desta escritura.

A seguir, sempre perante as mesmas testemunhas, pelo Exmo. Sr. Curador de Resíduos desta Comarca, Doutor Mario de Salles Penteado, me foi dito que aprovava os presentes estatutos e autorizava o seu registro.

De como assim disseram, dou fé; a pedido das partes e por distribuição de hoje, lavrei esta escritura, que lhes li, em presença das testemunhas, e, por acharem-na conforme, a outorgaram, aceitaram e assinam com essas testemunhas, que são: Dr. Henrique Smith Bayma, solteiro, e 
Dr. Ruy Martins Ferreira, casado, ambos advogados, residentes nesta Capital e meus conhecidos. Eu, José Bernardes Oliveira, escrevente habilitado, a escrevi sob minuta. Eu, O. Uchoa da Veiga, tabelião, a subscrevo.

(a.a.) Luiz Antonio da Gama e Silva Waldemar Martins Ferreira

Ernesto de Morais Leme

Honorio Fernandes Monteiro

Sylvio Marcondes

Oscar Barreto Filho

Philomeno Joaquim da Costa

Luiz de Oliveira Coutinho

Mario de Salles Penteado

Henrique Smith Bayma

Rùy Martins Ferreira 